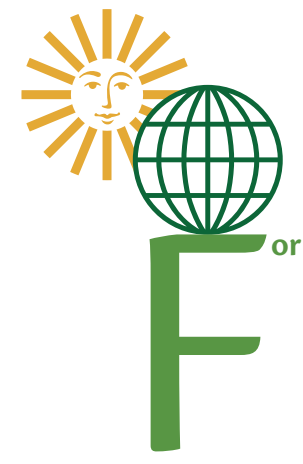

\title{
UC scientists help California prepare for climate change
}

or all the alarming signs of climate change - from earlier springs to melting polar ice - the overwhelming scientific consensus is that we haven't seen anything yet. Climate change is likely to accelerate greatly over the next century, with temperatures expected to climb faster than they have in the last 10,000 years.

California farmers face an uncertain future, where current crops may fail and water may be even more scarce. To help them adapt, UC researchers are finding ways to cut emissions of the greenhouse gases behind climate change, and to lessen their impacts on agriculture and wildlands (see box).

"There are no easy solutions," says UC Davis ecologist Louise Jackson. "Everything will be complicated by tradeoffs."

Globally, the average temperature is expected to rise another $2^{\circ} \mathrm{F}$ to $10^{\circ} \mathrm{F}$ on top of the $1^{\circ} \mathrm{F}$ increase since 1900, according to the Intergovernmental Panel on Climate Change (IPCC) (see page 59). While the world and the United States as a whole have gotten wetter, the Western states are likely to become drier. In addition to these broad changes, heat waves and rainstorms are likely to intensify.

Efforts to control climate change have focused on developed countries, which have contributed most of the carbon dioxide, methane, nitrous oxide and other greenhouse gases since the Industrial Revolution. But that is now shifting. China just became the world's largest greenhouse-gas contributor and is likely to increase its carbon emissions at least 11\% from 2004 to 2010, which is twice as fast as previously predicted, according to a recent study by UC Berkeley environmental economist Maxmillian Auffhammer and UC San Diego economist Richard Carson.

This underscores the fact that climate change cannot be tackled unilaterally, despite California's AB32 mandate to bring carbon emissions back to 1990 levels by 2020. In addition, because it takes so long for plankton in the oceans to clear carbon dioxide from the atmosphere, temperatures will still be higher mid-century even if we cut emissions today. Rather, the greatest impacts will be in the second half of the century, when temperatures are projected to increase most rapidly.

As a relatively small greenhouse-gas contributor at $7 \%$ of the state's total emissions, agriculture is unlikely to be heavily regulated. In fact, farmers could benefit from regulation by selling credits for reduced emissions on the carbon market (see page 96). Moreover, many ways of controlling agricultural emissions - such as drip irrigation, conservation tillage and dairy methane digesters - will have the added benefit of making farming more sustainable (see pages $79,84,91$ ).

In the Sacramento-San Joaquin River Delta, researchers are studying the potential of "carboncapture" farming to trap atmospheric carbon dioxide and rebuild soils lost to subsidence. A pilot study on Twitchell Island (shown) raised soils 10 inches between 1997 and 2005 , as cattails, tules and other plants grew, died and decomposed. The 3-year, \$12.3 million project joins scientists from UC Davis and the U.S. Geological Survey.

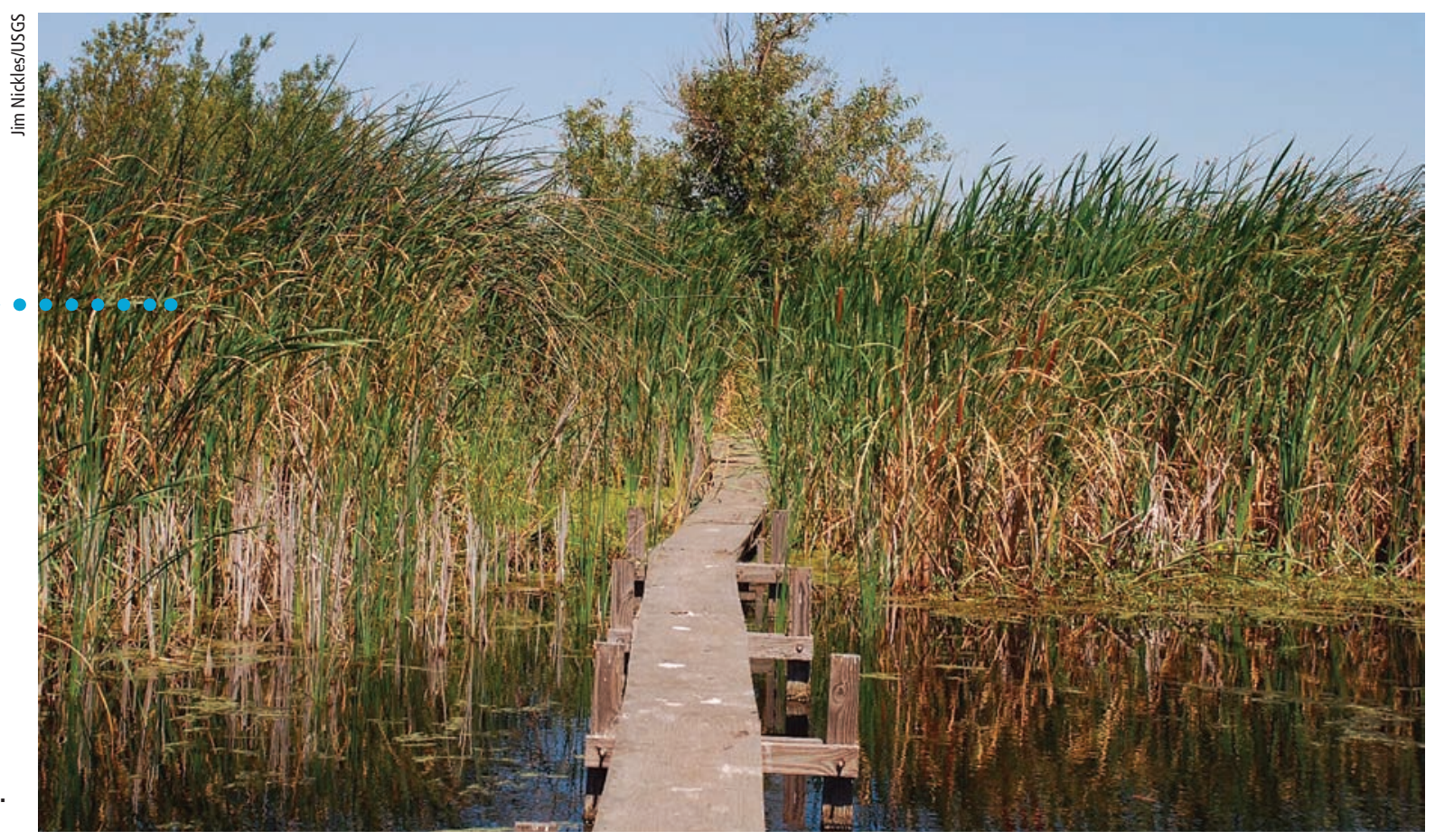




\section{Curbing tractor emissions}

One of the best ways of reducing greenhouse gases is to use less fossil fuel, the source of most carbon dioxide emissions. Studies during the 1990s showed that farmers can cut tractor fuel use from $6 \%$ to $20 \%$ by decreasing the tire pressure, says Shrini Upadhyaya, UC Davis agricultural and biological engineer. "Farmers often set tire pressure at 24 pounds per square inch (psi) but may be able to go down to 6 psi, depending on the load," he says, adding that while many farmers don't like to see the tires bulge, they can actually sit quite low. The biggest gains in fuel economy are in tilled fields during the spring, when the soil is a bit wet. Another benefit of lower pressure is that more of the tire surface touches the soil, reducing compaction (see California Agriculture 50[2]:28-31).

A drawback of lower tire pressure is that it is not optimal for all driving surfaces. "We knew it was good in the field but didn't know how well it would work on paved roads," Upadhyaya says. The recent increase in fuel prices prompted a followup study, which showed that tractors on roads are more fuel efficient at higher rather than lower tire pressures: increasing the pressure to 23 psi cuts fuel use by $12 \%$. But farmers cannot be expected to adjust their tire pressure every time they switch from driving on a field to driving on a paved road, and vice versa. To circumvent this, Upadhyaya envisions designing tractors that automatically adjust their tire pressure to fit the driving surface, as some military vehicles already do.

Now, however, the project is on hold once more. "While interest went up with the recent high gas prices, it then went down again," says Upadhyaya. "But the technology is there."

\section{Carbon-capture farming}

In addition to reducing their emissions, farmers can help remove carbon dioxide from the air. A technique called "carbon-capture" farming capitalizes on plants' ability to absorb atmospheric carbon dioxide and then trap the carbon in soil upon decomposing. Soils grew 10 inches higher over 7 years in wetland test plots on a Sacramento-San Joaquin River Delta island, according to a recent pilot study by UC Davis and U.S. Geological Survey researchers.

"Wetlands can capture carbon at a tremendous rate," says UC Davis soil biogeochemist William Horwath. An acre can grow about 15 tons of plant material per year, which contains about 8 tons of

\section{Climate change threatens California's native plants}

Recent research shows that the next century of climate change could drastically shrink the ranges of California's endemic plants, nearly 2,400 species that are unique to the state and help make it a global biodiversity hotspot. In the worst-case scenario, two-thirds of these plants could lose more than $80 \%$ of their current ranges.

"Plants are very sensitive to climate," says UC Berkeley plant ecologist David Ackerly, part of the team that reported this work in a 2008 Public Library of Science (PLoS) ONE study called "Climate Change and the Future of California's Endemic Flora." "The rate of climate change is now 3 to 10 times faster than at the end of the last ice age." This is so fast that many plants just won't be able to keep up.

Many of today's familiar landscapes could shift or even disappear in the future, the study predicts. As temperatures rise and rainfall becomes more variable, California's plants will generally move north and coastward to cooler areas. More specifically, coast redwoods could grow farther north, Sonoran desert plants could move into the Central Valley, and oaks could die out in the middle of the state.

Plants on mountain slopes may fare best, Ackerly says. If their current habitat gets too hot, they could easily reach cooler sites by moving a bit higher upslope. In contrast, plants growing on mountaintops would have nowhere to go, and those growing in flat areas would have to move tremendous - and unrealistic - distances.

"California's ruggedness may turn out to

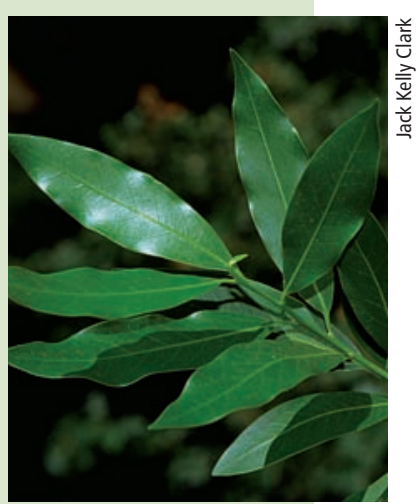

The native California bay in the coastal mountains and Sierra Nevada foothills, could see its range diminish dramatically. laurel, currently widespread be one of its greatest buffers against climate change," Ackerly says. Conservation planners could apply this finding to mountainous areas such as the coast ranges, the Sierra Nevada foothills and the San Gabriel Mountains east of Los Angeles. One approach entails establishing a network of protected areas at various elevations, connected by corridors to let plants move up as the temperature rises.

Another approach is for us to help the plants move. "It's cost-prohibitive for animals but not so crazy to think about for plants," Ackerly says. "We do restoration ecology all the time." Called managed relocation, this approach is hotly debated among conservationists, who prize preserving species in their natural habitats. Still, it may be time to turn traditional conservation on its head and "ask what will live on a reserve in the future versus where a given species can live," Ackerly says. Forestry could benefit from this approach without sparking controversy, since timberlands are managed plantations of native trees. To plan for harvests in 30 to 40 years, foresters could move seeds now in accord with expected climate changes.

Dire as the projections are, there is still hope for California's plants. "While most seeds drop right by the parent, jays can move acorns a third of a mile and wind-dispersed seeds can move many miles," Ackerly says. "It only takes a few long distance migrants to jump-start a new population."

- Robin Meadows 
carbon. Of that, $90 \%$ is lost to bacterial decomposition and the rest is captured in soil. The Delta is particularly well suited to carbon-capture farming. "It's one of the most productive ecosystems on the planet," says Horwath, who is also the UC Sustainable Agriculture Farming Systems (SAFS) project leader. "There are lots of nutrients and the climate is ideal."

Besides removing carbon from the air, rebuilding the Delta island soils would help protect the levees that route drinking water to

For more information AB32 Fact Sheet http://www.arb.ca.gov/cc/factsheets/ ab32factsheet.pdf

California Climate Change Portal http://www.climatechange.ca.gov

UC Davis: Climate Change Terms and Definitions

http://climatechange.ucdavis.edu/ terms.html

UC Davis John Muir Institute of the Environment, climate change science http://climatechange.ucdavis.edu/ index.html two-thirds of Californians. The levees are in danger of caving in because after years of draining and tilling the fragile peat soils, most of the islands lie 20 feet below the surrounding water. "We have created monsters in these islands," Horwath says. "It would be a catastrophe if the levees broke during an earthquake."

Because much of this land is privately owned, it cannot simply be flooded to protect the levees. Instead, the researchers hope to give Delta farmers another option. Instead of vegetable crops, Horwath envisions the farmers planting cattails, tule rushes and other wetland vegetation, and then selling the carbon credits. "They would be land stewards, growing carbon," he says. To assess the feasibility of carbon-capture farming, the researchers are scaling their study up to 400 acres. Possible pitfalls include the fact that wetlands emit methane, potentially outweighing the benefits of the carbon dioxide they remove from the air.

\section{Yolo County case study}

While many studies focus on specific ways to combat or cope with climate change, a UC Davis team took a comprehensive look at what Yolo County can expect - and what to do about it in the coming decades. Led by ecologist Louise Jackson, the 13-member interdisciplinary team included agricultural and natural resources researchers as well as social scientists. Sponsored by the California Energy Commission, the study benefited from a steering committee that included farmers, county and state representatives, and farm advisors.

"Overall, the single most important thing for growers is how to deal with specific crops that may be affected by heat waves, droughts and higher temperatures," Jackson says.

For example, over the next 50 years, Yolo County will likely get too hot for the warm-season crops that thrive there today, such as tomatoes, cucumbers, sweet corn and peppers. Instead, the future climate will suit melon, sweet potatoes and other hot-season crops during the summer, and lettuce, broccoli and other cool-season crops during the winter. Ways of helping farmers prepare include fostering markets for new crops, and breeding crops that tolerate longer, hotter heat waves and other climate extremes.

Farmers can also help themselves by growing more kinds of crops, which should make their operations more resilient to climate change. The current trend in Yolo County is toward less crop diversity, with seven types accounting for $85 \%$ of farmed land (see pages 84,91). Crop choices are driven by factors including how lucrative they are, the availability of local processors and economies of scale. However, "farmers also need to think about diversification and trying new crops," Jackson says.

The study also showed that as snow melts earlier in the Sierra Nevada and coincides with spring rains, marginal farmlands near the Sacramento River will be more likely to flood. "Marginal lands are present on every farm, along edges and riparian areas," Jackson says. "We can put these lands to work for increasing habitat, biodiversity and water quality." For example, rather than abandoning land that floods to weeds, farmers could create wetlands that store carbons and sell the resulting credits.

But while such restoration would capture carbon, this might be offset by the natural wetland emissions. Similarly, there are trade-offs with many of the other ways farmers can reduce their greenhouse-gas emissions. Two practices with clear-cut benefits are using less fuel and less nitrogen fertilizer, which is overapplied by as much as 50\% and can contribute to nitrous oxide emissions. Nitrous oxide is a powerful greenhouse gas, with about 300 times the impact of carbon dioxide. Besides being good for the environment, reducing fuel and fertilizer use is "good for the bottom line," Jackson says.

One practice that is not so clear-cut is drip irrigation, the study found. By keeping much of the soil dry, drip irrigation decreases carbon dioxide and nitrous oxide emissions from soil microorganisms. But partly because this practice requires fuel for pressurization, it also increases carbon emissions. Conversely, conservation tillage decreases fuel use but can also increase soil moisture and thus microorganism emissions. Likewise, cover cropping can capture carbon and decrease fertilizer use, but the plant residue also emits carbon dioxide during decomposition.

Farmers will have to weigh the various approaches for adapting to climate change. "Rather than giving one solution, we explain the costs and benefits and let people choose what works for them," Jackson says. 